Discussion Paper No. 642

\title{
WELFARE ANALYSIS OF DEBT POLICY DURING RECESSIONS
}

\author{
Takayuki Ogawa \\ The Seventh ISER-Moriguchi Prize (2005) \\ Awarded Paper
}

September 2005

The Institute of Social and Economic Research

Osaka University

6-1 Mihogaoka, Ibaraki, Osaka 567-0047, Japan 


\title{
Welfare Analysis of Debt Policy during Recessions
}

\author{
TAKAYUKI OGaWA ${ }^{1}$ \\ Kyoto University, Japan
}

\begin{abstract}
This paper develops an overlapping-generations model with nominal wage rigidities and examines the welfare effects of debt policy when unemployment exists. Issues of public debt stimulate aggregate consumption demand and create employment. Future generations then face both increased wage incomes and higher taxes. If the amount of outstanding bonds is already large, debt policy deteriorates the welfare of future generations by levying heavy taxes. By contrast, if the outstanding bond issue is relatively small, debt policy can be Pareto improving by creating more employment. Therefore, the welfare implications of debt policy during recessions can be discriminated from those during booms.
\end{abstract}

JEL Classification: E12, E24, E62, H63

Keywords: Debt policy, Overlapping generations, Welfare effects

Correspondence: Institute of Economic Research, Kyoto University, Yoshida-Honmachi, Sakyo-ku, Kyoto 606-8501, JAPAN. E-mail address: ogawa@kier.kyoto-u.ac.jp

\footnotetext{
${ }^{1}$ This paper received the Osaka University Institute of Social and Economic Research Moriguchi Prize in February 2005. I thank Koichi Futagami, Shinsuke Ikeda, Hiroshi Nakaota, Yoshiyasu Ono, Tadashi Shigoka, and seminar participants at the 2004 Spring Meeting of the Japanese Economic Association and Osaka University for their helpful comments. This research is financially supported by the Grant-in-Aid for JSPS Fellows, the Ministry of Education, Culture, Sports, Science and Technology.
} 


\section{INTRODUCTION}

Tobin (1980) asserts that in conditions of under-employment further issues of public debt stimulate aggregate demand and increase output and employment. Inspired by Tobin, Rankin (1986) demonstrates that when there are demand shortages and unemployment, such Keynesian debt policy brings higher steady-state social welfare. And more recently, Ono (2001) contends that, in the context of liquidity traps, current debt issue never places a burden on future generations. By way of contrast with the Keynesian scenario, Modigliani (1961) argues that debt issue puts a strain on future generations, even with under-employment situations. Accordingly, whether debt policy during recessions is beneficial to future generations remains a controversial issue. By introducing nominal wage rigidities into a monetary overlapping-generations model $\grave{a}$ la Weil (1987), this paper clarifies the welfare implications of debt policy during recessions.

In considering the problem of a burden on future generations of public debt, the definition of future generations is crucial. According to Lerner (1948), future generations are defined as people who exist at future dates irrespective of birth dates. On the other hand, Bowen et al. (1960) regard people who were born at the same date as the same generation, and define future generations as people who will be born after the present date. The analyses that approach the problem by using overlapping-generations models, including the current paper, follow the latter definition.

Another important point involved in analyzing this problem is whether the analysis uses an overlapping-generations model à la Diamond (1965) or one à la Blanchard (1985) and Weil $(1987,1989)$. In the Diamond model, people undoubtedly die and hence the current generation that enjoys benefit from debt issue never exists at far future dates. Therefore, the focus of the analysis is mainly drawn to the future level of output. Assuming full employment, Diamond (1965) shows that debt issue interferes with capital accumulation and lowers the steady-state level of output and welfare (if the economy is dynamically efficient). By contrast, developing 
the Diamond model with fixed prices and wages, Rankin (1986) finds that debt issue raises the steady-state level of output and welfare. Consequently, in the Diamond situation, debt policy is harmful to future generations during booms, whereas it is beneficial during recessions (as long as the economy is dynamically efficient). ${ }^{2}$

On the other hand, the Blanchard-Weil model examines the situation where the current generation exists even at far future dates. ${ }^{3}$ Then, the literature on the lines of Blanchard and Weil focuses mainly on the income redistribution effect between different generations of government policy. As shown in Blanchard (1985) and Weil (1989), debt finance means an income transfer from future generations to existing generations. It is because part of taxes associated with debt issue is levied on future generations, which are not connected with existing generations. Based on this intergenerational income redistribution effect, debt policy during booms is beneficial to existing generations and harmful to future generations (unless the economy is dynamically inefficient). ${ }^{4}$

The purpose of this paper is to examine the welfare implications of debt policy during recessions in the context of Blanchard and Weil. Taking into account both the intergenerational income redistribution effect and the existence of unemployment, the result differs from that of Diamond (1965), Rankin (1986), and Blanchard (1985)-Weil (1989). A further issue of public debt

\footnotetext{
${ }^{2}$ Sen (2002) points out that, in the Diamond model with monopolistic competition, debt finance can be Pareto improving depending on production technology.

${ }^{3}$ Blanchard assumes that people face a constant instantaneous probability of death throughout their lifetimes and thus the average rest of lives at some date is identical for all generations. Buiter (1988) concludes that, in the Blanchard model, the role of finite lifetimes is negligible and the appearance of new generations is rather more important, like the Weil model. Weil assumes that infinitely-lived agents appear at a constant rate. One justification of such a situation is primogeniture through inheritance of bequest. See Weil (1989) for other justifications.
}

${ }^{4}$ Saint-Paul (1992) also demonstrates that in an endogenous growth model with overlapping generations and production externalities, debt policy reduces the growth rate and welfare of some future generations. 
stimulates aggregate consumption demand and decreases unemployment, thereby supporting the Keynesian scenario. However, future generations face both this beneficial effect of increased wage incomes and the harmful effect of higher taxes. If the amount of outstanding bonds is relatively small and there is high population growth, debt policy enhances the welfare of future generations through creating more employment and is Pareto improving (even if the economy is dynamically efficient). Conversely, debt policy diminishes the welfare of future generations by levying heavy taxes if the outstanding issue is already large.

Section II presents the structure of the model. By using a simplified model without capital accumulation and wage adjustment, Section III clarifies the essence of debt policy during recessions. Section IV considers two extensions. The first incorporates capital accumulation. It shows that, as Modigliani (1961) is concerned, debt issue discourages investment and can lead to low levels of steady-state output if the prevailing interest rate lies at relatively low levels. This possibility barely changes the prime welfare implication obtained in Section III, because the economy is in dynamic-inefficiency at low levels of the interest rate. The second studies the role of wage adjustment. It shows that while a big fall in the nominal wage rate leads to full employment, the welfare implication of debt policy is basically the same as that of Section III if wage adjustment is sufficiently sluggish to preserve unemployment. Section V summarizes and concludes.

\section{THE MODEL}

\section{II.A. Consumers}

The basic structure of the model is the same as that of Weil (1987), i.e., a hybrid of a money-in-utility model and an overlapping-generations model, except for nominal wage rigidities. Economy starts at time 0 . The size of initial population is normalized to unity. At each point in time, new infinitely-lived consumers appear at the rate $n(>0)$. The total population at time 
$t$ is hence obtained as $N(t)=e^{n t}$.

Given the time paths of the real interest rate $\{r(t)\}_{t=s}^{\infty}$, the nominal interest rate $\{R(t)\}_{t=s}^{\infty}$, the real wage rate $\{w(t)\}_{t=s}^{\infty}$, and the lump-sum $\operatorname{tax}\{\tau(s, t)\}_{t=s}^{\infty}$, a consumer representative of the cohort born at time $s(\geq 0)$ chooses $\{c(s, t), k(s, t), b(s, t), m(s, t)\}_{t=s}^{\infty}$ to maximize the lifetime utility,

$$
U(s, s) \equiv \int_{s}^{\infty}[(1-\alpha) \ln c(s, t)+\alpha \ln m(s, t)] e^{-\rho(t-s)} \mathrm{d} t
$$

subject to

$$
\begin{aligned}
& \frac{\mathrm{d} a(s, t)}{\mathrm{d} t}=r(t) a(s, t)+w(t) x(s, t)-c(s, t)-R(t) m(s, t)-\tau(s, t), \\
& a(s, t) \equiv k(s, t)+b(s, t)+m(s, t), \\
& c(s, t) \geq 0, \quad m(s, t) \geq 0, \\
& a(0,0)>0, \quad a(s, s)=0 \quad \text { for } \forall s>0, \\
& \lim _{t \rightarrow \infty} a(s, t) e^{-\int_{s}^{t} r(v) \mathrm{d} v} \geq 0,
\end{aligned}
$$

where the constant parameter $\alpha$ satisfies $\alpha \in(0,1), \rho(>0)$ is the subjective discount rate, and $c(s, t)$ is consumption at time $t(\geq s)$ of a consumer born at time $s .{ }^{5}$ For simplicity, labor endowment of each consumer is normalized to unity. To consider unemployment, however, the realized labor supply is denoted by $x(s, t)$. Equation (3) implies that total non-human wealth $a(s, t)$ consists of capital $k(s, t)$, public bonds $b(s, t)$, and real money balances $m(s, t)$. Equation (5) indicates that the initial generation is endowed with positive non-human wealth; whereas, for lack of bequest motives of pre-existing generations, none of new generations receives non-human wealth at birth.

\footnotetext{
${ }^{5}$ To characterize the instantaneous utility function by a more general CES form does not add further insights.
} 
The first-order conditions are

$$
\begin{aligned}
\frac{\mathrm{d} c(s, t)}{\mathrm{d} t} & =[r(t)-\rho] c(s, t), \\
R(t) & =\frac{\alpha}{1-\alpha} \frac{c(s, t)}{m(s, t)},
\end{aligned}
$$

and the above constraints. Equations (2) and (6)-(8) yield the individual consumption function

$$
c(s, t)=\rho(1-\alpha)[a(s, t)+h(s, t)]
$$

where $h(s, t)$ is the net human wealth defined as

$$
h(s, t)=\int_{t}^{\infty}[w(z) x(s, z)-\tau(s, z)] e^{-\int_{t}^{z} r(v) \mathrm{d} v} \mathrm{~d} z .
$$

Define the aggregate consumption per capita $c(t)$ as $c(t)=\frac{c(0, t)+\int_{0}^{t} c(s, t) \mathrm{d} N(s)}{N(t)}$. Same definitions hold for other variables: $a(t), k(t), b(t), m(t), x(t), \tau(t)$, and $h(t)$. By applying this aggregation rule to (8) and (9), I have

$$
\begin{aligned}
R(t) & =\frac{\alpha}{1-\alpha} \frac{c(t)}{m(t)}, \\
c(t) & =\rho(1-\alpha)[a(t)+h(t)] .
\end{aligned}
$$

\section{II.B. Production}

Using physical capital and labor, competitive firms produce a commodity used for consumption and investment. Firms have identical production technology. For analytical tractability, the production function is specified by the Cobb-Douglas form: $y(t)=\theta k(t)^{\beta} l(t)^{1-\beta}$, which is expressed in aggregate per capita. $y(t)$ is the aggregate output per capita and $l(t)$ the aggregate labor demand per capita. $\theta(>0)$ and $\beta$ respectively measure productivity and capital share in output. In particular, this paper assumes $\beta \in\left[0, \frac{1}{2}\right)$ of which analytical meaning is presented in 
Section IV.A. ${ }^{6}$ The optimization by firms provides

$$
\begin{aligned}
r(t) & =\beta \theta\left[\frac{k(t)}{l(t)}\right]^{\beta-1}, \\
w(t) & =(1-\beta) \theta\left[\frac{k(t)}{l(t)}\right]^{\beta} .
\end{aligned}
$$

\section{II.C. Government}

The government budget constraint is

$$
\frac{\mathrm{d} b(t)}{\mathrm{d} t}=[r(t)-n] b(t)-\mu(t) m(t)-\tau(t)
$$

which is expressed in aggregate per capita. I omit the role of fiscal spending and distortional taxes for purpose of comparison with the literature. $\mu(t)$ is the expansion rate of nominal money supply. Letting $\pi(t)$ be the inflation rate, this paper assumes that $\mu(t)=\pi(t)+n$ for $\forall t$, so that $m(t)$ remains at $\bar{m}(>0)$. Unless $\mu(t)=\pi(t)+n$ holds for $\forall t$, either full employment or zero employment is eventually attained through the Pigou effect. ${ }^{7}$

Following the existing studies, I characterize debt policy as follows. At time 0, government increases $b(0)$ through a helicopter drop; and after time 0 , aims to keeping it constant at that value, $\bar{b}(>0)$.

\section{DEBT POLICY DURING RECESSIONS}

\section{III.A. Simple setting}

To elicit the essence of debt policy during recessions, I establish the following simple setting. First, in this section, the nominal wage rate is permanently fixed at a given level, $\bar{W}{ }^{8}$ Hence, unemployment may arise.

\footnotetext{
${ }^{6}$ This range regarding $\beta$ includes its plausible values used in the standard $\mathrm{RBC}$ literature. For example, King and Rebelo (1999) set $\beta$ equal to one-thirds.

${ }^{7}$ See e.g., Ono $(1994,2001)$.

${ }^{8}$ Rankin (1986) also follows this exogenously-fixed-prices approach ̀̀ la Barro and Grossman (1971) and Malinvaud (1977). Blanchard and Kiyotaki (1987) show nominal price/wage rigidity to arise as a consequence of
} 
Second, throughout the paper, I assume the distribution rule that labor demand and lumpsum taxes are identical across agents: $x(s, t)=\min (1, l(t))$ and $\tau(s, t)=\tau(t) .{ }^{9}$ Then, $h(s, t)$ is an age-independent variable: $h(s, t)=h(t)$.

Third, this section imposes $\beta=0$, so that the role of capital accumulation is set aside and labor is a unique production input. Given the nominal wage rigidity, the commodity market is in equilibrium if and only if $\frac{\bar{W}}{P(t)}=\theta$, where $P(t)$ denotes the price level. $P(t)$ is instantaneously adjusted to satisfy this value, which is henceforth labelled $\bar{P}$. As the inflation rate is always zero, the nominal value of $m(t)$ remains at $\bar{M}(=\bar{m} \bar{P}>0)$ and that of $b(t)$ at $\bar{B}(=\bar{b} \bar{P}>0)$. The real interest rate equals the nominal interest rate: $r(t)=R(t)$.

III.B. Steady state and welfare

Keeping the distribution rule in mind, (2), (5), (8), (10), and (12) together derive the dynamic equation for $c(t)$,

$$
\frac{\mathrm{d} c(t)}{\mathrm{d} t}=[r(t)-\rho] c(t)-\rho n(1-\alpha) a(t)
$$

This equation implies that the amount of assets affects aggregate consumption streams for lack of bequest motives. ${ }^{10}$ From $(11),(16)$, and $a(t)=\frac{\bar{B}}{\bar{P}}+\frac{\bar{M}}{\bar{P}}$, the aggregate dynamic system is characterized by

$$
\frac{\mathrm{d} r(t)}{\mathrm{d} t}=r(t)^{2}-\rho r(t)-\rho n \alpha \frac{\bar{B}+\bar{M}}{\bar{M}}
$$

As seen in Figure 1, there is a unique steady state, $r^{*}$, with $r(t)>0$, which is determined by

$$
r^{* 2}-\rho r^{*}-\rho n \alpha \frac{\bar{B}+\bar{M}}{\bar{M}}=0 .
$$

monopolistic agents' behavior in the presence of menu costs. See Mankiw and Romer (1991) for microfoundations of price/wage rigidities.

${ }^{9} \mathrm{I}$ can employ the age-dependent income schedule used in Blanchard (1985), but it does not alter the main result of this paper.

${ }^{10}$ Refer to Blanchard (1985) and Weil (1989) for this point. 


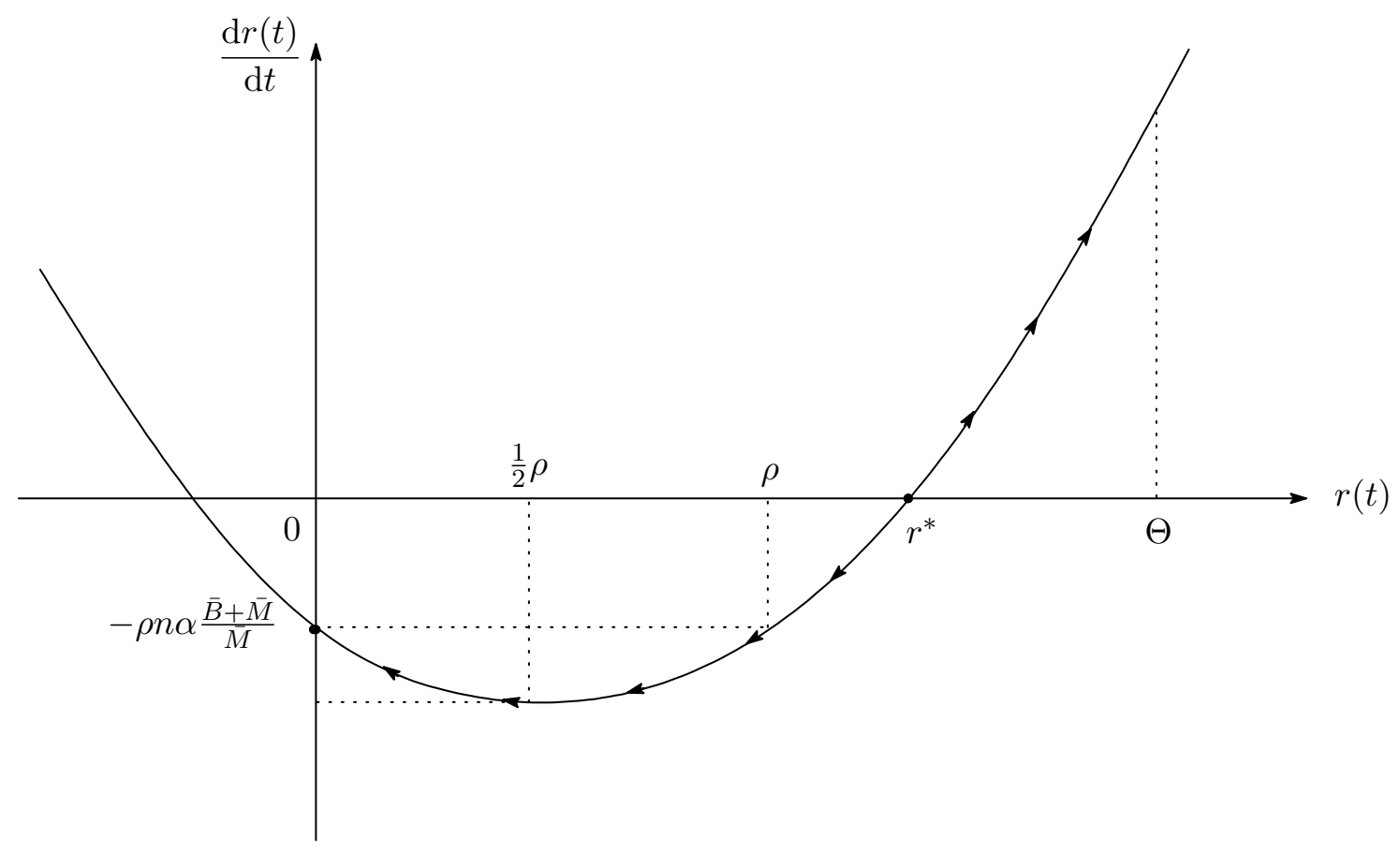

Figure 1: Aggregate Dynamics.

The steady state associated with $r^{*}$ is unstable. If $r(t)$, or equivalently $c(t)$, evolves along the divergent paths, either the intertemporal budget constraint of the consumer or the non-negativity constraint on consumption is violated. Therefore, $r^{*}$ must be chosen at the initial point in time. In Figure $1, \Theta \equiv \frac{\alpha}{1-\alpha} \frac{\theta \bar{P}}{M}$ represents the interest rate associated with full employment. To take account of unemployment, I set $\Theta$ above $r^{*}$.

As in Blanchard (1985) and Weil $(1987,1989)$, the non-negativity on individual consumption requires $r^{*} \leq \rho+n \cdot{ }^{11}$ Substituting $\bar{B}=0$ into (17) gives the lower bound of $r^{*}$, which is labelled $\underline{\mathrm{r}}^{*}$ and satisfies $\underline{\mathrm{r}}^{*}>\rho$. As a result, $r^{*}$ must be in the following range:

Condition 1. $\underline{\mathrm{r}}^{*}<r^{*} \leq \rho+n$.

\footnotetext{
${ }^{11}$ From (5) and (9), the non-negativity of individual consumption is satisfied if and only if $h(s, s)$ is non-negative for all $s>0$. Equation (12) implies that $h(s, s) \geq 0$ is equivalent to $c(t) \geq \rho(1-\alpha)\left(\frac{\bar{B}}{P}+\frac{\bar{M}}{\bar{P}}\right)$, which, together with (17), generates this condition.
} 
From (15), the steady-state lump-sum tax $\tau^{*}$ is

$$
\tau^{*}=r^{*} \frac{\bar{B}}{\bar{P}}-n\left(\frac{\bar{B}}{\bar{P}}+\frac{\bar{M}}{\bar{P}}\right) .
$$

Next, I derive welfare. In the absence of the transition process, substituting (8) into (1) yields

$$
U(s, s)=\int_{s}^{\infty} \ln c(s, t) e^{-\rho(t-s)} \mathrm{d} t-\frac{\alpha}{\rho} \ln R^{*}+\frac{\alpha}{\rho} \ln \frac{\alpha}{1-\alpha},
$$

where $R^{*}\left(=r^{*}\right)$ denotes the steady-state nominal interest rate. The first term in the right-hand side of this equation represents the gross lifetime utility derived from both consumption and holding money. The second term implies the opportunity costs of holding money. By use of (7) and (9), welfare is reduced to ${ }^{12}$

$$
U(s, s)=\frac{1}{\rho} \ln r^{*}[a(s, s)+h(s, s)]-\frac{\alpha}{\rho} \ln R^{*}+\frac{1}{\rho} \ln \alpha^{\alpha}(1-\alpha)^{1-\alpha} .
$$

Letting $c^{*}$ be the steady-state consumption, $h(s, s)$ is obtained as $h(s, s)=\frac{c^{*}-\tau^{*}}{r^{*}}$ from (10) and the equilibrium condition in the commodity market. Equation (19) is eventually rewritten as

$$
U(s, s)=\frac{1}{\rho} \ln \left[r^{*} a(s, s)+c^{*}-\tau^{*}\right]-\frac{\alpha}{\rho} \ln R^{*}+\frac{1}{\rho} \ln \alpha^{\alpha}(1-\alpha)^{1-\alpha},
$$

which says that the gross lifetime utility is increasing with respect to the net income at birth, that is, $r^{*} a(s, s)+c^{*}-\tau^{*}$.

\section{III.C. Comparative statics}

This subsection examines the effects of an increase in $\bar{B}$. First, I show its implication as the Keynesian demand-management policy, which is emphasized by Tobin (1980).

Lemma 1. Debt policy raises the interest rate.

Proof. Differentiating (17) totally and using Condition 1, I get $\frac{\mathrm{d} r^{*}}{\mathrm{~d} \bar{B}}=\frac{\rho n \alpha}{\left(2 r^{*}-\rho\right) M}>0$.

\footnotetext{
${ }^{12}$ See e.g., Futagami and Shibata $(1999,2003)$ and Mino and Shibata (2000) for details of the derivation. In deriving this formula, I used the approximate expression of $\ln (1+\epsilon)=\epsilon$.
} 
Proposition 1. Debt policy stimulates aggregate consumption demand.

Proof. Use of (11) and Lemma 1 gives $\frac{\mathrm{d} c^{*}}{\mathrm{~d} \bar{B}}=\frac{\rho n(1-\alpha)}{\left(2 r^{*}-\rho\right) \bar{P}}>0$.

Consideration of the intergenerational income redistribution effect of debt finance is sufficient to explain this proposition. That is, unless wage income changes, debt policy increases total wealth of existing generations and decreases that of future generations through higher taxes. Therefore, existing generations consume more and future generations less. The total effect on aggregate consumption is definitely positive because part of future generations that consume less does not yet appear in the economy. Consequently, the larger amount of assets induces more aggregate consumption demand for lack of a consumption-smoothing motive across generations. Since the resultant rise in wage income does not disturb this explanation, increasing non-human wealth through debt policy becomes an effective demand-management policy.

As implied by (20), the level of the net income at birth is crucial for welfare. I next examine the effect on $r^{*} a(s, s)+c^{*}-\tau^{*}$.

Lemma 2. Debt policy raises the net income of the initial generation at birth.

Proof. Taking notice of $a(0,0)=\frac{\bar{B}}{\bar{P}}+\frac{\bar{M}}{\bar{P}}$ and using (18) and Lemma 1, I get $\frac{\mathrm{d}\left[r^{*} a(0,0)-\tau^{*}\right]}{\mathrm{d} \bar{B}}=$ $\frac{\bar{M}}{\bar{P}} \frac{\mathrm{d} r^{*}}{\mathrm{~d} \bar{B}}+\frac{n}{\bar{P}}>0$. Together with Proposition $1, \frac{\mathrm{d}\left[r^{*} a(0,0)+c^{*}-\tau^{*}\right]}{\mathrm{d} \bar{B}}>0$.

The interpretation of Proposition 1 is also applied to this lemma. Because part of taxes associated with debt issue is levied on future generations, which are not connected with existing generations, public bonds become net wealth for existing generations. That is, debt policy raises $r^{*} a(0,0)-\tau^{*}$. Combined with the demand-stimulating effect (Proposition 1), the net incomes of existing generations undoubtedly rise.

Meanwhile, I have the following:

Lemma 3. Debt policy raises the net incomes of future generations at birth if $\underline{r}^{*}<r^{*}<\frac{2}{3}(\rho+n)$ and reduces those if $\max \left(\underline{r}^{*}, \frac{2}{3}(\rho+n)\right)<r^{*} \leq \rho+n$. 
Proof. Notice $a(s, s)=0$. Differentiating (18) totally and combining it with Proposition 1 yield $\frac{\mathrm{d}\left(c^{*}-\tau^{*}\right)}{\mathrm{d} \bar{B}}=\frac{-3 r^{*}\left[r^{*}-\frac{2}{3}(\rho+n)\right]}{\left(2 r^{*}-\rho\right) \bar{P}}$ in which $\bar{B}$ is eliminated by use of $(17)$. Condition 1 ensures the denominator to be positive. The numerator is positive if $0<r^{*}<\frac{2}{3}(\rho+n)$ and negative if $\frac{2}{3}(\rho+n)<r^{*}$. Taking into account Condition 1, the proof is completed.

The intuitive interpretation of this lemma is as follows. Since $\frac{\mathrm{d}^{2} c^{*}}{\mathrm{~d} \bar{B}^{2}}=\frac{-2 \rho n(1-\alpha)}{\left(2 r^{*}-\rho\right)^{2} \bar{P}} \frac{\mathrm{d} r^{*}}{\mathrm{~d} \bar{B}}<0$ is satisfied, the marginal effect on aggregate demand decreases. The source of this result is that an expansion in consumption raises the interest rate simultaneously and consumers postpone consumption demand through intertemporal choices. On the other hand, the relation between $\tau^{*}$ and $\bar{B}$ satisfies

$$
\begin{aligned}
\frac{\mathrm{d} \tau^{*}}{\mathrm{~d} \bar{B}} & =\frac{\bar{B}}{\bar{P}} \frac{\mathrm{d} r^{*}}{\mathrm{~d} \bar{B}}+\frac{r^{*}-n}{\bar{P}} \\
\frac{\mathrm{d}^{2} \tau^{*}}{\mathrm{~d} \bar{B}^{2}} & =\frac{2\left[3 r^{*}\left(r^{*}-\rho\right)+\rho(\rho+n \alpha)\right]}{\left(2 r^{*}-\rho\right)^{2} \bar{P}} \frac{\mathrm{d} r^{*}}{\mathrm{~d} \bar{B}}>0 .
\end{aligned}
$$

The first term in the right-hand side of (21) represents increased tax by a rise in the interest rate. The second term in the right-hand side of $(21)$ is negative when $r^{*}<n$ but positive when $r^{*}>n$. As illustrated in Figure 2(a) and 2(b), there are two possible cases concerning the schedule of $\tau^{*}$. In the figures, $\bar{B}^{P} \equiv \frac{\bar{M}}{\rho \alpha}[n-\rho(1+\alpha)]$ is the $\bar{B}$ corresponding to $r^{*}=n$, and $\bar{B}^{U} \equiv \frac{\bar{M}}{\rho \alpha}[n+\rho(1-\alpha)]$ represents the upper bound of $\bar{B}$ that gives $r^{*}=\rho+n$. Figure 2(a) depicts the case with a Ponzi scheme (i.e., $\left.\bar{B}^{P}>0\right)$, in the words of Weil (1989). At $\bar{B} \in\left(0, \bar{B}^{P}\right), r^{*}<n$ is satisfied and lump-sum transfers exceed seigniorages $\left(\tau^{*}<-n \frac{\bar{M}}{\bar{P}}\right)$. At $\bar{B} \in\left(\bar{B}^{P}, \bar{B}^{U}\right]$, I have $r^{*}>n$ and $\tau^{*}>-n \frac{\bar{M}}{\bar{P}}$, so that $\tau^{*}$ is increasing with respect to $\bar{B}$. Figure $2(\mathrm{~b})$ describes the case without a Ponzi scheme (i.e., $\left.\bar{B}^{P} \leq 0\right)$. In this case, debt issue always involves higher taxes. As shown in (22), the marginal effect on taxes increases because debt issue raises the interest rate simultaneously.

For these reasons, the schedule of $c^{*}-\tau^{*}$ falls into two patterns, Figure 3(a) and 3(b). In the figures, $\bar{B}^{M} \equiv \frac{\bar{M}}{9 \rho n \alpha}\left(-2 \rho^{2}+4 n^{2}+2 \rho n-9 \rho n \alpha\right)$ is the $\bar{B}$ that attains $r^{*}=\frac{2}{3}(\rho+n)$, and satisfies that $\frac{\mathrm{d} \bar{B}^{M}}{\mathrm{~d} n}=\frac{2}{9} \frac{\bar{M}\left(\rho^{2}+2 n^{2}\right)}{\rho n^{2} \alpha}>0$. If population growth is relatively low, I obtain Figure 


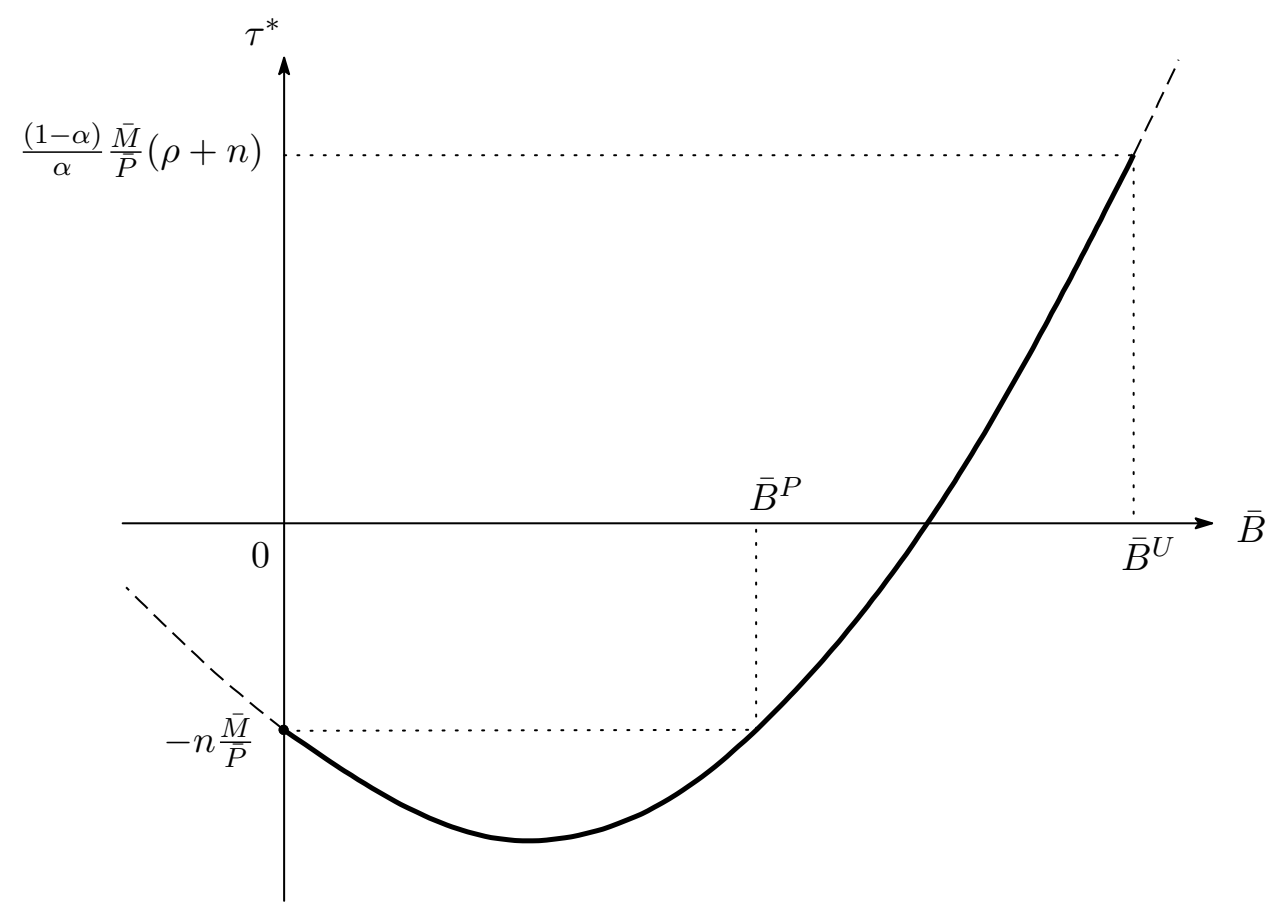

Figure 2(a): $\bar{B}^{P}>0$.

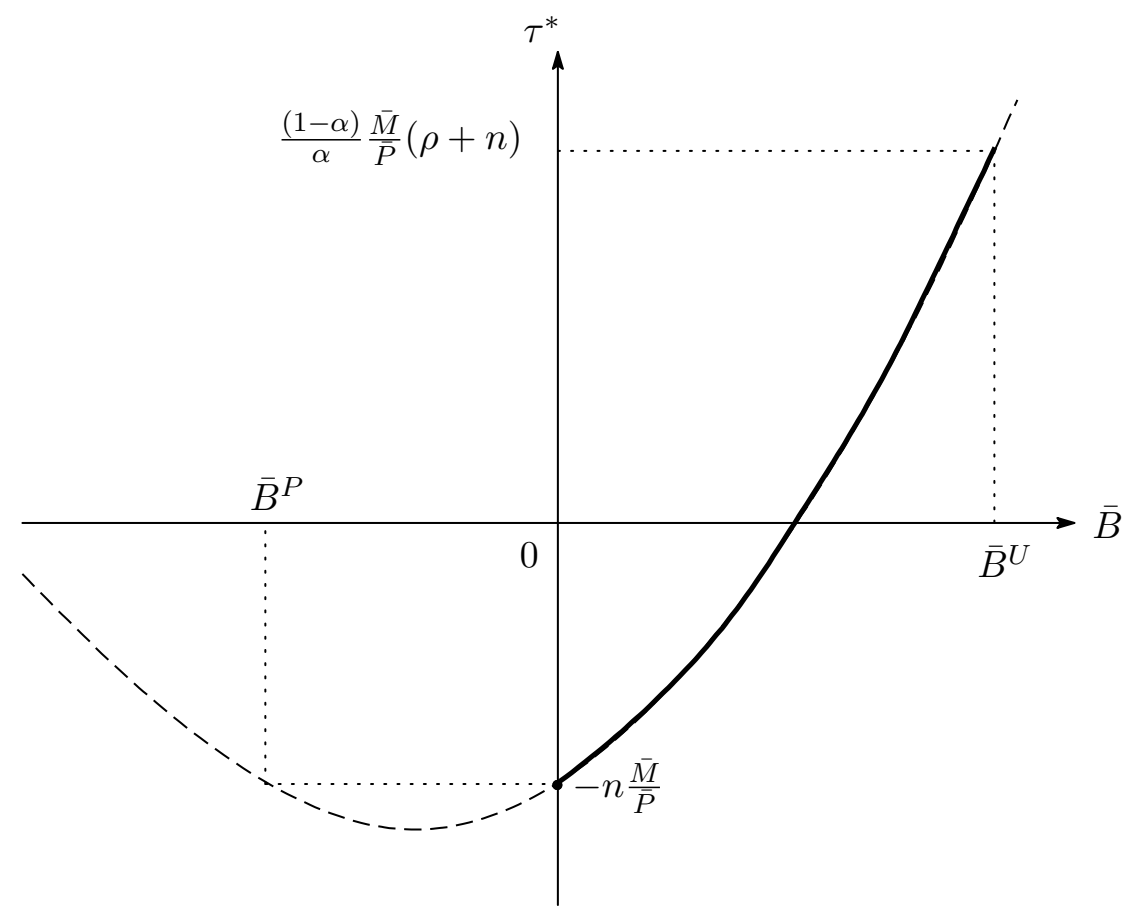

Figure 2(b): $\bar{B}^{P} \leq 0$. 


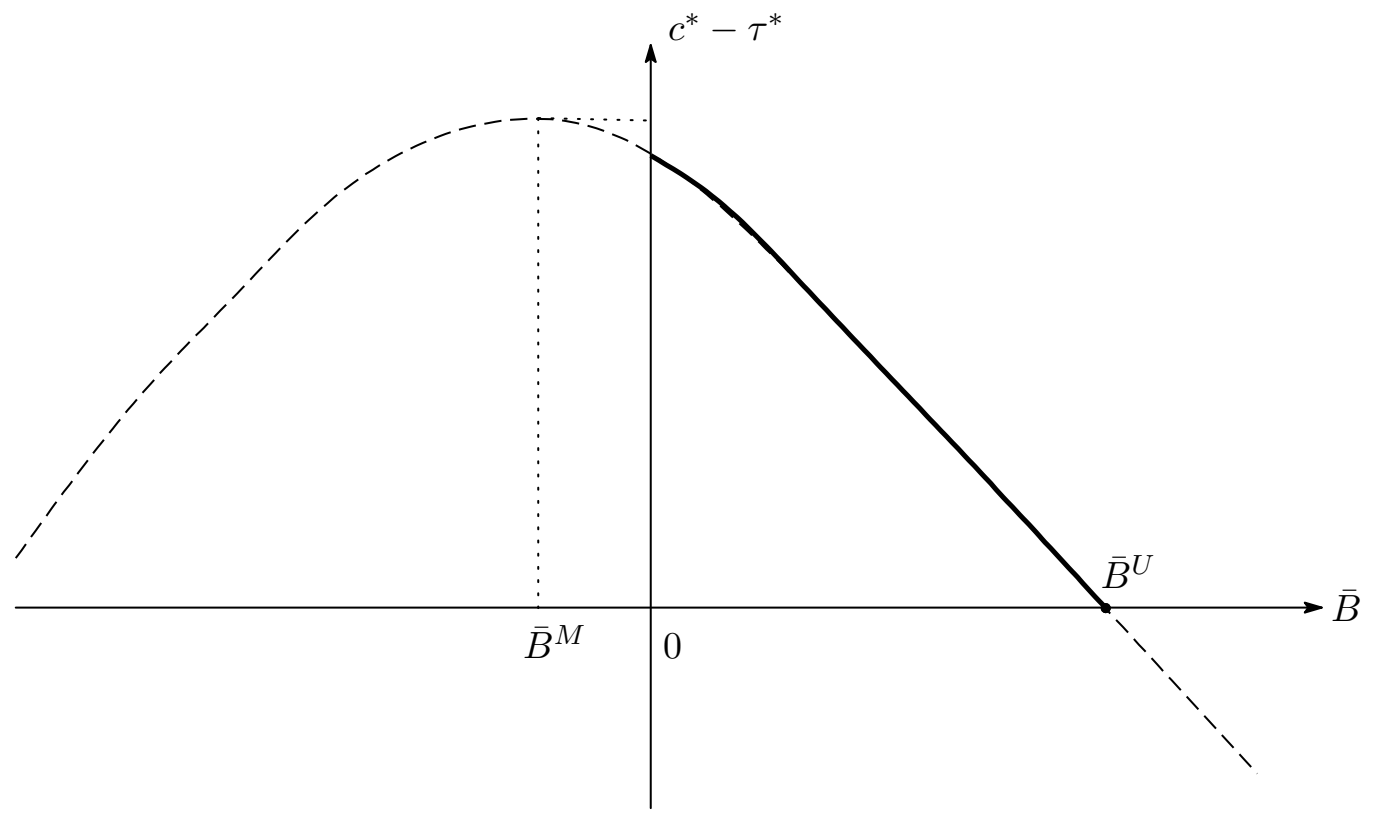

Figure $3(\mathrm{a}): \bar{B}^{M} \leq 0$.

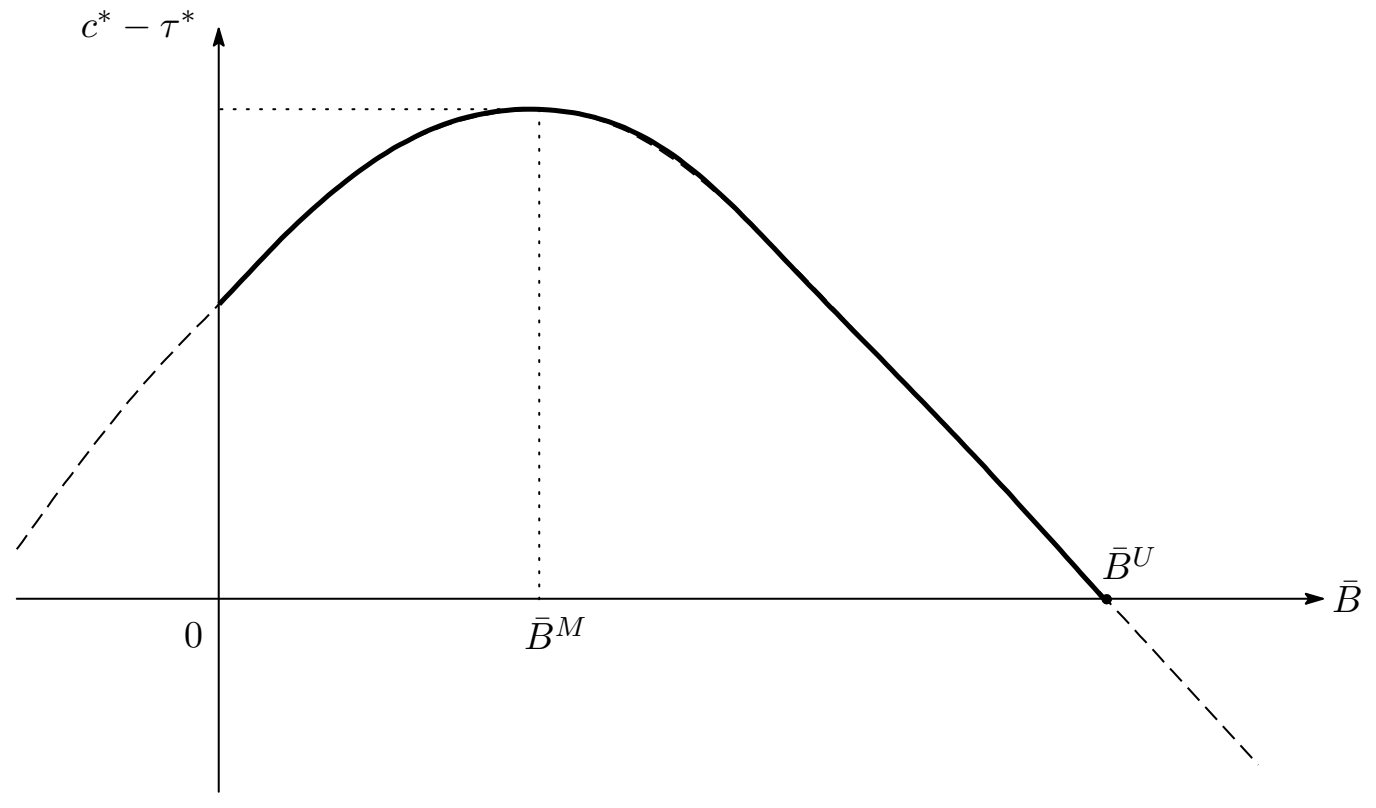

Figure $3(\mathrm{~b}): \bar{B}^{M}>0$. 
3(a) with $\bar{B}^{M} \leq 0$, where debt policy always reduces the net incomes of future generations by levying heavy taxes. On the contrary, if there is enough high population growth, I get Figure 3(b) with $\bar{B}^{M}>0$. Because high population growth brings the large demand-stimulating effect, debt policy raises the net incomes of future generations at $\bar{B} \in\left(0, \bar{B}^{M}\right)$. However, the demandstimulating effect decreases with issuing of bonds. When $\bar{B}$ reaches $\bar{B}^{M}$, debt policy reduces $c^{*}-\tau^{*}$ like Figure $3(\mathrm{a})$.

Remark 1. It is easy to prove that $\bar{B}^{P}>0$ is not necessary condition but sufficient condition for $\bar{B}^{M}>0$. At $\bar{B} \in\left(\bar{B}^{P}, \bar{B}^{M}\right)$, debt policy raises the net incomes of all generations despite a non-Ponzi scheme.

Lemma 2 and 3 directly derive the welfare implication:

Theorem 1. If $\underline{r}^{*}<r^{*}<\frac{2-\alpha}{3-\alpha}(\rho+n)$, debt policy is Pareto improving. If $\max \left(\underline{r}^{*}, \frac{2-\alpha}{3-\alpha}(\rho+n)\right)<r^{*} \leq \rho+n$, debt policy improves welfare of the initial generation but deteriorates that of future generations.

Proof. See Appendix A.

Remark 2. $\frac{2-\alpha}{3-\alpha}(\rho+n)<\frac{2}{3}(\rho+n)$, which reflects the fact that an increase in $\bar{B}$ brings the higher interest rate and the higher cost of holding money.

Differently from models with full employment (e.g., Blanchard 1985 and Weil 1989), when there is high population growth and the amount of outstanding bonds is relatively small, debt policy during recessions is Pareto improving by creating more employment (even if the economy is dynamically efficient). However, as public debt accumulates, the demand-stimulating effect declines whereas the cost through taxes swells. Consequently, when the outstanding issue is large, future generations are made worse off by heavy taxes. The result is also different from Rankin (1986) where debt policy during recessions is always beneficial to future generations. 


\section{ExTENSIONS}

IV.A. Capital accumulation

Modigliani's (1961) original concern is the crowding-out effect of public debt: capital accumulation is discouraged by raising the interest rate and welfare of future generations falls. The contribution of Rankin (1986) challenges this negative scenario by showing that debt issue increases the steady-state output and welfare. For purpose of comparison, this section pays attention also to the effect on capital accumulation.

The optimal conditions (13) and (14) generate

$$
r(t)=\beta \theta\left[\frac{\bar{W}}{(1-\beta) \theta P(t)}\right]^{\frac{\beta-1}{\beta}} .
$$

Since the equilibrium condition of asset markets ensures $a(t)=k(t)+\frac{\bar{B}}{P(t)}+\frac{\bar{M}}{P(t)}$, the dynamic equation for $c(t)$ becomes

$$
\frac{\mathrm{d} c(t)}{\mathrm{d} t}=[r(t)-\rho] c(t)-\rho n(1-\alpha)\left[k(t)+\frac{\bar{B}}{P(t)}+\frac{\bar{M}}{P(t)}\right] .
$$

Keeping $y(t)=\frac{r(t) k(t)}{\beta}$ in mind, the equilibrium condition of the commodity market is

$$
\frac{\mathrm{d} k(t)}{\mathrm{d} t}=\frac{r(t) k(t)}{\beta}-c(t)-n k(t)
$$

The Fisher equation and (11) yield

$$
\frac{\mathrm{d} P(t)}{\mathrm{d} t}=\left[\frac{\alpha}{1-\alpha} \frac{c(t) P(t)}{\bar{M}}-r(t)\right] P(t) .
$$

Equations (23)-(26) constitute the autonomous dynamic system.

Appendix B proves that the steady state is uniquely determined if it exists, and is dynamically stable. The analysis assumes the existence of the steady state. See Appendix B for the mathematical proof of the following argument.

To explain the effect on the steady-state values $\left(c^{*}, k^{*}, P^{*}\right)$, I propose three channels displayed in Figure 4. By the same logic as Proposition 1, Channel 1 signifies that taking $\left(r^{*}, k^{*}, P^{*}\right)$ as 


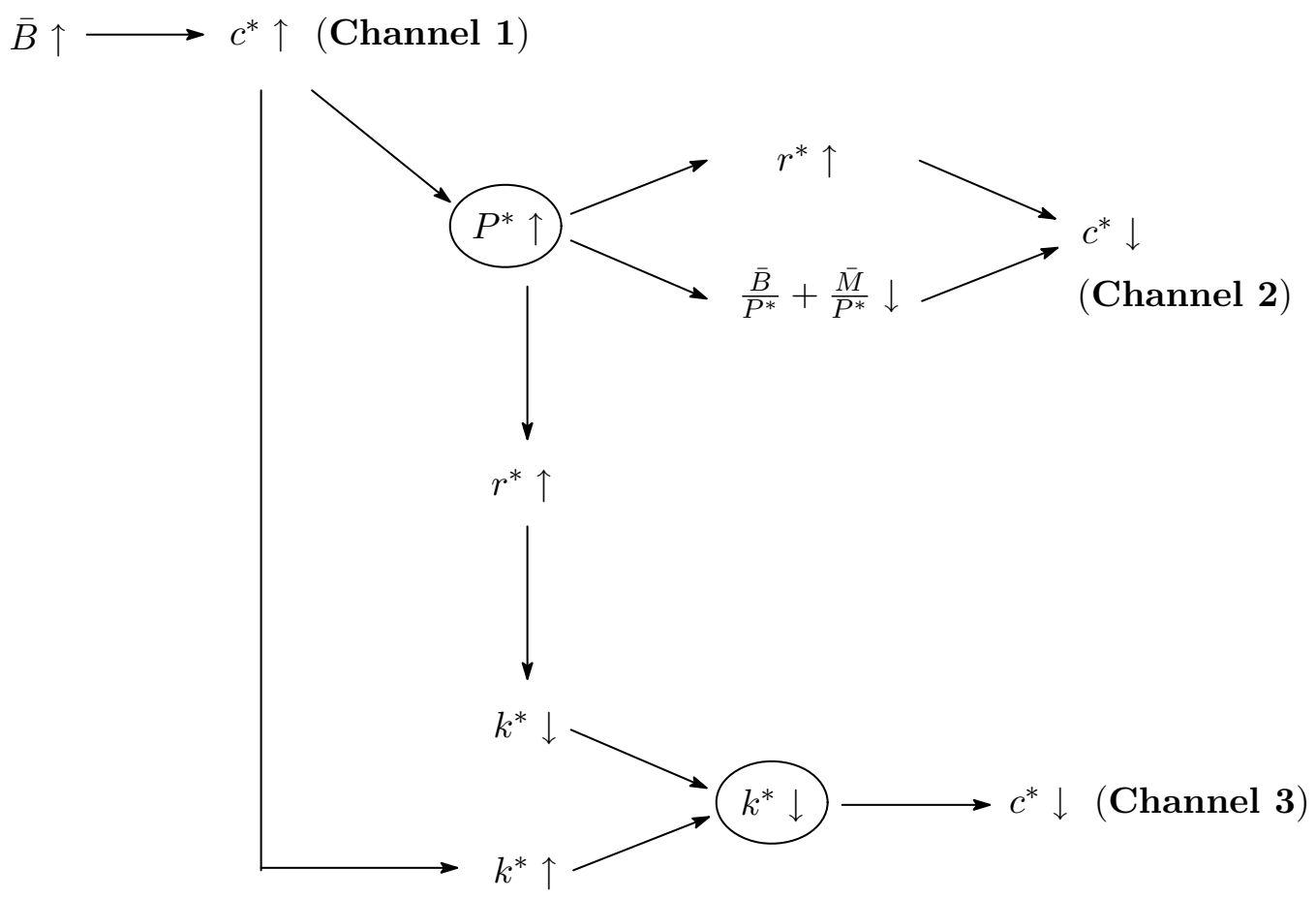

Figure 4: Channels.

given in (24), debt policy directly raises $c^{*}$. Starting this point, there are two secondary effects denoted by Channel 2 and 3. From (23) and (26), I find that an increase in $c^{*}$ raises $P^{*}{ }^{13}$ In turn, $r^{*}$ rises from (23) and $\frac{\bar{B}}{P^{*}}+\frac{\bar{M}}{P^{*}}$ falls. Equation (24) implies that these secondary effects put downward pressure on $c^{*}$ (Channel 2). Equation (25) shows that there are conflicting effects on $k^{*}$ : the demand-stimulating effect of Channel 1 directly raises $k^{*}$ but indirectly reduces it through raising $r^{*}$. I can prove that $k^{*}$ totally falls. Equation (24) implies that this secondary effect puts downward pressure on $c^{*}($ Channel 3$)$. Dynamic stability $($ Det $<0)$ ensures that $c^{*}$ totally rises through Channel 1-3. I conclude that debt policy increases $c^{*}$ and $P^{*}$ and decreases $k^{*}$.

Responding to this result, the total effect on the steady-state output, $y^{*}=c^{*}+n k^{*}$, is ambiguous. When the prevailing interest rate is relatively low (i.e., $r^{*}<\frac{n \beta(3 \beta-2)}{2 \beta-1}$ ), the marginal

\footnotetext{
${ }^{13}$ This result depends on $\beta \in\left(0, \frac{1}{2}\right)$. If $\beta$ exceeds $\frac{1}{2}$, an increase in $c^{*}$ reduces $P^{*}$. Then, the total effects are negative on $c^{*}$, ambiguous on $k^{*}$, and positive on $P^{*}$.
} 
crowding-out effect is large and debt policy is harmful to aggregate output. Modigliani's (1961) scenario holds true in this case: debt policy reduces future aggregate output through crowding out investment. However, the total effect including a change in taxes is much more important. Assuming that the economy is always in steady state, I obtain the welfare implication. ${ }^{14}$

Proposition 2. If $\underline{r}^{*}<r^{*}<\frac{2-3 \beta-\alpha(1-\beta)}{3-4 \beta-\alpha(1-\beta)}(\rho+n)$, debt policy is beneficial to all generations. If $\max \left(\underline{r}^{*}, \frac{2-3 \beta-\alpha(1-\beta)}{3-4 \beta-\alpha(1-\beta)}(\rho+n)\right)<r^{*} \leq \rho+n$, debt policy improves welfare of the initial generation and deteriorates that of future generations.

Proof. See Appendix B.

Remark 3. $\frac{2-3 \beta-\alpha(1-\beta)}{3-4 \beta-\alpha(1-\beta)}(\rho+n)<\frac{2-\alpha}{3-\alpha}(\rho+n)$, which reflects the fact that an increase in $\bar{B}$ accompanies the negative effect through crowding out investment.

Basically, the implication of Theorem 1 is inherited even if capital accumulation is incorporated. Although there is the possibility that aggregate output drops, the economy is in dynamicinefficiency at low levels of the interest rate. Therefore, if there is high population growth and the amount of outstanding bonds is small, debt finance improves welfare of all generations whether aggregate output drops or not.

\section{IV.B. Wage adjustment}

In the real world, deflation or a reduction in the nominal wage rate is often observed during recessions. This subsection examines the effects of wage adjustment on debt policy. From the theoretical viewpoint, they are divided into (i) the rate-of-change effect and (ii) the level effect.

The effect of a rate of change of prices is first investigated. Assume that the nominal wage rate is adjusted by the rate $\phi\left(\frac{W(t)}{W(t)}=\phi\right)$. The price level is also adjusted by the rate $\phi$

\footnotetext{
${ }^{14}$ Under the same assumption, Futagami and Shibata (2003) examine the welfare effects of government budget deficits in an endogenous growth model with overlapping generations.
} 
$\left(\pi(t)=\frac{\dot{P(t)}}{P(t)}=\phi\right)$ to satisfy $\frac{W(t)}{P(t)}=\theta$. The aggregate dynamic system is then rewritten as

$$
\frac{\mathrm{d} r(t)}{\mathrm{d} t}=[r(t)-\rho][r(t)+\phi]-\rho n \alpha \frac{\bar{b}+\bar{m}}{\bar{m}} .
$$

To obtain a unique unstable steady state with $r(t)>0$, the analysis assumes $n \alpha+\phi>0$. The steady state, which must be chosen at the initial point in time, is characterized by (20),

$$
\begin{aligned}
& \left(r^{*}-\rho\right)\left(r^{*}+\phi\right)-\rho n \alpha \frac{\bar{b}+\bar{m}}{\bar{m}}=0, \\
& r^{*}=R^{*}-\phi=\frac{\alpha}{1-\alpha} \frac{c^{*}}{\bar{m}}-\phi, \\
& \tau^{*}=\left(r^{*}-n\right) \bar{b}-(\phi+n) \bar{m} .
\end{aligned}
$$

Proposition 3. If $\underline{r}^{*}<r^{*}<r^{* M}$, debt policy is beneficial to all generations. If $\max \left(\underline{r}^{*}, r^{* M}\right)<$ $r^{*} \leq \rho+n$, debt policy improves welfare of the initial generation and deteriorates that of future generations. $r^{* M}$ is given by $r^{* M} \equiv \frac{[(2-\alpha)(\rho+n)-2 \phi]+\sqrt{[(2-\alpha)(\rho+n)-2 \phi]^{2}+4 \phi(3-\alpha)(\rho+n)}}{2(3-\alpha)}$.

Proof. See Appendix C.

Remark 4. $r^{* M}>\frac{2-\alpha}{3-\alpha}(\rho+n)$ for $\phi<0$.

Deflation raises $r^{*}$ for given $R^{*}$ and reduces seigniorages. Hence, aggregate consumption demand diminishes and taxes increase $\left(\frac{\mathrm{d}\left(c^{*}-\tau^{*}\right)}{\mathrm{d} \phi}>0\right)$. According to the mechanism explained in Section III, this means that the marginal welfare effect of debt issue increases (Remark 4). Obviously, this rate-of-change effect barely changes the prime implication of Theorem 1 .

The effect of a level of prices is established in the following proposition.

Proposition 4. A fall in the nominal wage rate $\bar{W}$ stimulates aggregate consumption demand through the Pigou effect, but it does not alter the welfare implication of Theorem 1.

Proof. From $\frac{\bar{W}}{P(t)}=\theta$ and (17), I obtain $\frac{\mathrm{d} r^{*}}{\mathrm{~d} W}=0$. Combined with (11), this gives $\frac{\mathrm{d} c^{*}}{\mathrm{~d} W}=-\frac{c^{*}}{W}<0$. From (18), I have $\frac{\mathrm{d} \tau^{*}}{\mathrm{~d} W}=-\frac{\tau^{*}}{W}$. Keeping Theorem 1 in mind, these results bring $\frac{\mathrm{d}^{2} U(s, s)}{\mathrm{d} B \mathrm{~d} W}=0$ for $\forall s \geq 0$ 
Remark 5. If full employment is achieved by a big fall in $\bar{W}$, the welfare implication alters significantly, that is, the Blanchard-Weil result is applied.

This proposition indicates that the duration of recessions is crucial in assessing a burden on future generations of public debt. However, it should be noted that if policy makers can pay back the debt as soon as reaching full employment, Theorem 1 is directly applied during recessions without modification.

The two propositions demonstrate that the welfare implication of Theorem 1 is basically inherited as long as wage adjustment is sufficiently sluggish to preserve unemployment.

\section{Conclusion}

The present paper develops an overlapping-generations model with nominal wage rigidities and examines the welfare effects of debt policy during recessions. Further issues of public debt stimulate aggregate consumption demand and create employment. In so doing, future generations face both this beneficial employment effect and higher taxes. As public debt accumulates, the beneficial effect gradually declines whereas the harmful effect steadily swells. If the outstanding issue is already large, heavy taxes lower the welfare of future generations. In contrast, if the outstanding issue is relatively small and there is high population growth, the beneficial effect dominates the harmful effect and debt policy is Pareto improving (even if the economy is dynamically efficient). These welfare implications are different from the results obtained in both the Blanchard-Weil model with full employment and the Diamond model with unemployment.

There are some directions for future research. For instance, the following is useful in evaluating a burden of future generations accurately: (i) to consider the transitional dynamics of capital accumulation; to employ more realistic (ii) distribution rules across agents; (iii) fiscal and monetary policy; (iv) wage adjustment processes. 


\section{Appendix A. Proof of Theorem 1}

Differentiating (20) totally yields

$$
\begin{aligned}
\frac{\mathrm{d} U(0,0)}{\mathrm{d} \bar{B}} & =\frac{1}{\rho\left[r^{*} a(0,0)+c^{*}-\tau^{*}\right]} \frac{\mathrm{d}\left[r^{*} a(0,0)+c^{*}-\tau^{*}\right]}{\mathrm{d} \bar{B}}-\frac{\alpha}{\rho r^{*}} \frac{\mathrm{d} r^{*}}{\mathrm{~d} \bar{B}}, \\
\frac{\mathrm{d} U(s, s)}{\mathrm{d} \bar{B}} & =\frac{1}{\rho\left(c^{*}-\tau^{*}\right)} \frac{\mathrm{d}\left(c^{*}-\tau^{*}\right)}{\mathrm{d} \bar{B}}-\frac{\alpha}{\rho r^{*}} \frac{\mathrm{d} r^{*}}{\mathrm{~d} \bar{B}} \text { for } \forall s>0 .
\end{aligned}
$$

Rewrite $r^{*} a(s, s)+c^{*}-\tau^{*}$ as a function of $r^{*}$ and $\bar{B}$ by using (11) and (18). Eliminate $\bar{B}$ from the result and Lemma 2 by use of (17). Utilizing these results, Lemma 1, and 3, the welfare effect of a change in $\bar{B}$ is calculated as

$$
\begin{aligned}
\frac{\mathrm{d} U(0,0)}{\mathrm{d} \bar{B}} & =\frac{n(2-\alpha)}{\rho[a(0,0)+h(0,0)]\left(2 r^{*}-\rho\right) \bar{P}}>0, \\
\frac{\mathrm{d} U(s, s)}{\mathrm{d} \bar{B}} & =\frac{-(3-\alpha)\left[r^{*}-\frac{2-\alpha}{3-\alpha}(\rho+n)\right]}{\rho h(s, s)\left(2 r^{*}-\rho\right) \bar{P}} \text { for } \forall s>0 .
\end{aligned}
$$

The former equation is positive. The latter equation is positive if $0<r^{*}<\frac{2-\alpha}{3-\alpha}(\rho+n)$ and negative if $\frac{2-\alpha}{3-\alpha}(\rho+n)<r^{*}$. Taking account of Condition 1 completes the proof.

\section{APPENDiX B.}

Steady state and dynamic system

From (23)-(26), the steady state is, after tedious manipulations, characterized by

$$
\Phi\left(r^{*}\right) \equiv r^{* 3}-(\rho+n \beta) r^{* 2}-\rho n \alpha \frac{\bar{B}+(1-\beta) \bar{M}}{\bar{M}} r^{*}+\rho n^{2} \alpha \beta \frac{\bar{B}+\bar{M}}{\bar{M}}=0 .
$$

$r^{*}$ must satisfy the following conditions: (i) $r^{*} \geq \rho$, which is required for $c^{*} \geq 0$ from (24); (ii) $r^{*} \geq n \beta$, which is required for $k^{*} \geq 0$ from (25); (iii) $r^{*} \leq \rho+n$, which is the non-negativity constraint of individual consumption; (iv) $r^{*}>\underline{r}^{*}$, which defines the lower bound of $r^{*}$. I have $\Phi(0)=\rho n^{2} \alpha \beta \frac{\bar{B}+\bar{M}}{\bar{M}}>0, \Phi(\rho)=-\rho^{2} n(1-\alpha)-\rho n \alpha \frac{\bar{B}+\bar{M}}{\bar{M}}(\rho-n \beta)<0$ for $\rho \geq n \beta$, and $\Phi(n \beta)=-\rho n^{2}(1-\alpha) \beta^{2}<0$, so that $r^{*}$ is uniquely determined if it exists. Since $\underline{r}^{*}>\max (\rho, n \beta)$, the range of $r^{*}$ is summarized as

Condition 2. $\underline{\mathrm{r}}^{*}<r^{*} \leq \rho+n$. 
The dynamic system linearized around the steady state is

$$
\left(\begin{array}{c}
\frac{\mathrm{d} c(t)}{\mathrm{d} t} \\
\frac{\mathrm{d} k(t)}{\mathrm{d} t} \\
\frac{\mathrm{d} P(t)}{\mathrm{d} t}
\end{array}\right)=\left(\begin{array}{ccc}
r^{*}-\rho & -\rho n(1-\alpha) & \frac{1-\alpha}{\alpha} \frac{\bar{M}}{P^{* 2}}\left[\frac{1-\beta}{\beta} r^{* 2}+\rho n \alpha \frac{\bar{B}+\bar{M}}{\bar{M}}\right] \\
-1 & \frac{r^{*}-n \beta}{\beta} & \frac{1-\alpha}{\alpha} \frac{\bar{M}}{P^{* 2}} \frac{1-\beta}{\beta} \frac{r^{* 2}}{r^{*}-n \beta} \\
\frac{\alpha}{1-\alpha} \frac{P^{* 2}}{\bar{M}} & 0 & \frac{2 \beta-1}{\beta} r^{*}
\end{array}\right)\left(\begin{array}{c}
c(t)-c^{*} \\
k(t)-k^{*} \\
P(t)-P^{*}
\end{array}\right) .
$$

For this coefficient matrix,

$$
\begin{aligned}
\text { Trace } & =3 r^{*}-(\rho+n), \\
\text { Det } & =-\frac{1-\beta}{\beta^{2}} \frac{r^{*}}{r^{*}-n \beta} \psi\left(r^{*}\right)<0
\end{aligned}
$$

in which $\bar{B}$ is eliminated by use of the above steady-state condition. The function $\psi\left(r^{*}\right)$ is given by

$$
\psi\left(r^{*}\right) \equiv 2 r^{* 3}-(\rho+4 n \beta) r^{* 2}+2 n \beta(\rho+n \beta) r^{*}-\rho n^{2} \alpha \beta^{2}
$$

Det $<0$ is proved as follows. The first derivative of $\psi\left(r^{*}\right)$ is $\frac{\mathrm{d} \psi\left(r^{*}\right)}{\mathrm{d} r^{*}}=2\left(r^{*}-n \beta\right)\left[3 r^{*}-(\rho+n \beta)\right]$. First, consider the case where $\frac{\rho+n \beta}{3}<n \beta$. Because I have $\psi(n \beta)=\rho n^{2}(1-\alpha) \beta^{2}>0, \psi\left(r^{*}\right)>0$ is satisfied within Condition 2. Next, consider the case where $\frac{\rho+n \beta}{3} \geq n \beta$. Since $\frac{\rho+n \beta}{3}<\rho$ is satisfied, it is sufficient to show $\psi\left(r^{*}\right)>0$ for $r^{*} \geq \rho$. I have $\psi(\rho)=\rho(\rho-n \beta)^{2}+\rho n^{2} \beta^{2}(1-\alpha)>0$. Resultantly, $\psi\left(r^{*}\right)$ is always positive within Condition 2 and hence I get Det $<0$.

As $k(0)$ is predetermined and $c(0)$ and $P(0)$ are not, the steady state is dynamically stable: the dynamic path is either saddle-point stable or indeterminacy. In the case of saddle-point stability, divergent paths are inconsistent with the optimality of individual consumers.

\section{Comparative statics}

Differentiating the steady-state conditions totally, the steady-state effect of debt policy is obtained as

$$
\begin{aligned}
\frac{\mathrm{d} c^{*}}{\mathrm{~d} \bar{B}} & =\frac{\rho n(1-\alpha)(2 \beta-1) r^{*}\left(r^{*}-n \beta\right)}{\beta^{2} P^{*} \operatorname{Det}}>0, \\
\frac{\mathrm{d} k^{*}}{\mathrm{~d} \bar{B}} & =\frac{\beta^{2}\left[r^{*}-n(2 \beta-1)\right]}{(2 \beta-1)\left(r^{*}-n \beta\right)^{2}} \frac{\mathrm{d} c^{*}}{\mathrm{~d} \bar{B}}<0, \\
\frac{\mathrm{d} P^{*}}{\mathrm{~d} \bar{B}} & =-\frac{\beta}{(2 \beta-1) r^{*}} \frac{\alpha}{1-\alpha} \frac{P^{* 2}}{\bar{M}} \frac{\mathrm{d} c^{*}}{\mathrm{~d} \bar{B}}>0 .
\end{aligned}
$$


As explained in the text, Det $<0$ and the restriction on $\beta$ produce the above signs. From these results, I get the effect on the steady-state output, $y^{*}=c^{*}+n k^{*}$ :

$$
\frac{\mathrm{d} y^{*}}{\mathrm{~d} \bar{B}}=\frac{r^{*}}{\left(r^{*}-n \beta\right)^{2}}\left[r^{*}-\frac{n \beta(3 \beta-2)}{2 \beta-1}\right] \frac{\mathrm{d} c^{*}}{\mathrm{~d} \bar{B}} \geq 0 \quad \text { if } \quad r^{*} \geq \frac{n \beta(3 \beta-2)}{2 \beta-1} .
$$

By use of $w^{*} x^{*}=(1-\beta) y^{*}$, the restriction on $\beta$, and (15), the effect on the steady-state net wage income $w^{*} x^{*}-\tau^{*}$ is derived as

$$
\frac{\mathrm{d}\left(w^{*} x^{*}-\tau^{*}\right)}{\mathrm{d} \bar{B}}=\frac{(3-4 \beta) r^{*}\left[r^{*}-\frac{2-3 \beta}{3-4 \beta}(\rho+n)\right]}{\rho n(1-\alpha)(2 \beta-1)} \frac{\mathrm{d} c^{*}}{\mathrm{~d} \bar{B}} \geq 0 \quad \text { if } \quad r^{*} \leq \frac{2-3 \beta}{3-4 \beta}(\rho+n) .
$$

Assume that the economy is always in steady state. Following the similar procedure to Theorem 1, I obtain the welfare effect:

$$
\begin{aligned}
\frac{\mathrm{d} U(0,0)}{\mathrm{d} \bar{B}} & =\frac{1}{\rho[a(0,0)+h(0,0)]} \frac{-[2-3 \beta-\alpha(1-\beta)]}{\rho(1-\alpha)(2 \beta-1)} \frac{\mathrm{d} c^{*}}{\mathrm{~d} \bar{B}}>0, \\
\frac{\mathrm{d} U(s, s)}{\mathrm{d} \bar{B}} & =\frac{1}{\rho h(s, s)} \frac{[3-4 \beta-\alpha(1-\beta)]\left[r^{*}-\frac{2-3 \beta-\alpha(1-\beta)}{3-4 \beta-\alpha(1-\beta)}(\rho+n)\right]}{\rho n(1-\alpha)(2 \beta-1)} \frac{\mathrm{d} c^{*}}{\mathrm{~d} \bar{B}} \text { for } \forall s>0 .
\end{aligned}
$$

Notice that $3-4 \beta>2-3 \beta>\alpha(1-\beta)$. $\frac{\mathrm{d} U(s, s)}{\mathrm{d} \bar{B}}$ is positive if $r^{*}<\frac{2-3 \beta-\alpha(1-\beta)}{3-4 \beta-\alpha(1-\beta)}(\rho+n)$ and negative otherwise. Taking into account Condition 2, the proof of Proposition 2 is completed.

\section{Appendix C. Proof of Proposition 4}

Following the same procedure to Theorem 1, I get the welfare effect:

$$
\begin{aligned}
\frac{\mathrm{d} U(0,0)}{\mathrm{d} \bar{b}} & =\frac{n\left[(1-\alpha) r^{*}+\left(r^{*}+\phi\right)\right]}{\rho r^{*}[a(0,0)+h(0,0)]\left[2 r^{*}-(\rho-\phi)\right]}>0, \\
\frac{\mathrm{d} U(s, s)}{\mathrm{d} \bar{b}} & =\frac{\zeta\left(r^{*}\right)}{\rho r^{*} h(s, s)\left[2 r^{*}-(\rho-\phi)\right]} \quad \text { for } \forall s>0,
\end{aligned}
$$

where the function $\zeta\left(r^{*}\right)$ is given by

$$
\zeta\left(r^{*}\right) \equiv-(3-\alpha) r^{* 2}+[(2-\alpha)(\rho+n)-2 \phi] r^{*}+\phi(\rho+n) .
$$

$r^{*}$ must be in the following range:

Condition 3. $\underline{r}^{*}<r^{*} \leq \rho+n$. 
where $\underline{r}^{*}$ satisfies $\underline{r}^{*}>\max (\rho,-\phi)$. This ensures $\frac{\mathrm{d} U(0,0)}{\mathrm{d} b}$ to be positive. Letting $r^{* M}$ be the larger root of $\zeta\left(r^{*}\right)=0$ and $r^{* M-}$ be the smaller root, it is satisfied that $r^{* M-}<\underline{\mathrm{r}}^{*}$ and $r^{* M}<\rho+n$ if the steady state is unique $(n \alpha+\phi>0)$. Taking account of Condition $3, \frac{\mathrm{d} U(s, s)}{\mathrm{d} b}$ is positive if $\underline{\mathrm{r}}^{*}<r^{*}<r^{* M}$ and negative if $\max \left(\underline{\mathrm{r}}^{*}, r^{* M}\right)<r^{*} \leq \rho+n$.

\section{REFERENCES}

Barro, R.J., Grossman, H.I., 1971. A general disequilibrium model of income and employment. American Economic Review 61 (1), 82-93.

Blanchard, O.J., 1985. Debt, deficits, and finite horizons. Journal of Political Economy 93 (2), $223-247$.

Blanchard, O.J., Kiyotaki, N., 1987. Monopolistic competition and the effects of aggregate demand. American Economic Review 77 (4), 647-666.

Bowen, W.G., Davis, R.G., Kopf, D.H., 1960. The public debt: a burden on future generations?. American Economic Review 50 (4), 701-706.

Buiter, W.H., 1988. Death, birth, productivity growth and debt neutrality. Economic Journal 98 (391), 279-293.

Diamond, P.A., 1965. National debt in a neoclassical growth model. American Economic Review $55(5), 1126-1150$.

Futagami, K., Shibata, A., 1999. Welfare effects of bubbles in an endogenous growth model. Research in Economics 53 (4), 381-403.

Futagami, K., Shibata, A., 2003. Budget deficits and economic growth. Public Finance 53 (2-3), $331-354$. 
King, R.G., Rebelo, S.T., 1999. Resuscitating real business cycles. In Woodford, M., Taylor, J. (Eds.), Handbook of Macroeconomics, Vol. 1B. North-Holland, Amsterdam, 927-1007.

Lerner, A.P., 1948. The burden of the national debt. In Metzler, L.A. (Ed.), Income, Employment and Public Policy: Essays in Honor of Alvin H. Hansen, W.W. Norton \& Company, New York, 255-275.

Malinvaud, E., 1977. The Theory of Unemployment Reconsidered, Blackwell, Oxford.

Mankiw, N.G., Romer, D., 1991. New Keynesian Economics, Vols. 1 and 2. MIT Press, Cambridge, MA.

Mino, K., Shibata, A., 2000. Growth and welfare effects of monetary expansion in an overlappinggenerations economy. Japanese Economic Review 51 (3), 407-430.

Modigliani, F., 1961. Long-run implications of alternative fiscal policies and the burden of the national debt. Economic Journal 71 (284), 730-750.

Ono, Y., 1994. Money, Interest, and Stagnation: Dynamic Theory and Keynes's Economics, Oxford University Press, Oxford, England.

Ono, Y., 2001. A reinterpretation of chapter 17 of Keynes's general theory: effective demand shortage under dynamic optimization, International Economic Review 42 (1), 207-236.

Ono, Y., 2001. Gokai darake no Kouzou Kaikaku (in Japanese). Nihon Keizai Shinbun Sha, Tokyo, Japan.

Rankin, N., 1986. Debt policy under fixed and flexible prices. Oxford Economic Papers 38 (3), $481-500$.

Saint-Paul, G., 1992. Fiscal policy in an endogenous growth model. Quarterly Journal of Economics 107 (4), 1243-1259. 
Sen, P., 2002. Welfare-improving debt policy under monopolistic competition. Journal of Economic Dynamics \& Control 27 (1), 143-156.

Tobin, J., 1980. Asset Accumulation and Economic Activity. Basil Blackwell, Oxford.

Weil, P., 1987. Permanent budget deficits and inflation. Journal of Monetary Economics 20 (2), $393-410$.

Weil, P., 1989. Overlapping families of infinitely-lived agents. Journal of Public Economics 38 (2), 183-198. 